\title{
Cognitive decline among European retirees: impact of early retirement, nation-related and personal characteristics
}

\author{
Sara Carmel ${ }^{1,2 *}$ (D) and Aviad Tur-Sinai ${ }^{3}$ \\ ${ }^{1}$ Center for Multidisciplinary Research in Aging, Ben-Gurion University of the Negev, Beer-Sheva, Israel, \\ ${ }^{2}$ Department of Public Health, Ben-Gurion University of the Negev, Beer-Sheva, Israel and ${ }^{3}$ Department of \\ Health Systems Management, The Max Stern Yezreel Valley College, Yezreel Valley, Israel \\ *Corresponding author. Email: sara@bgu.ac.il
}

(Accepted 14 January 2021; first published online 10 March 2021)

\begin{abstract}
Our study aimed to enhance understanding of memory decline (MD) in old age by evaluating longitudinal effects of personal and national contributing factors. We used data collected by the Survey of Health, Ageing and Retirement in Europe (SHARE) from 12 European countries and Israel. Our sample included 11,930 retirees aged 50+, interviewed at baseline and four years later. MD was evaluated by the change in the number of recalled words from first to second interview. Except for gender, all of our explanatory variables had a significant unique effect on MD - age, education, type of occupation, European geographical region, early retirement, time elapsed from retirement, reason for retirement, active lifestyle, re-employment, health/function status, depressive symptoms, and decline in physical and mental health - over the four years of the study. Our findings indicate that MD can be postponed by national policies such as those which prolong years of education and participation in the workforce, and by social interventions directed to promote active lifestyles in late life, especially in Mediterranean and Eastern European nations.
\end{abstract}

Keywords: memory decline; early retirement; health/function; active lifestyle; depressive symptoms

\section{Introduction}

Since the mid-20th century, we have been witness to a worldwide unprecedented and continuing increase in life expectancy. However, the achievement of reaching this long-desired goal is accompanied by a decline in physical and cognitive functioning, and attenuation in meaningful activities and social contacts in later life (e.g. World Health Organization (WHO), 2017a, 2017b; Zeng et al., 2017). The harmful effects of these developments on the ever-growing population of older adults, their families and society impose significant challenges for ageing nations, some of which

(C) The Author(s), 2021. Published by Cambridge University Press on behalf of Ageing and Society. This is an Open Access article, distributed under the terms of the Creative Commons Attribution-NonCommercial-NoDerivatives licence (http:// creativecommons.org/licenses/by-nc-nd/4.0/), which permits non-commercial re-use, distribution, and reproduction in any medium, provided the original work is unaltered and is properly cited. The written permission of Cambridge University Press must be obtained for commercial re-use or in order to create a derivative work. 
are striving to ensure a reasonable level of quality-of-life for all parties involved, while attempting to reduce the related economic burden.

The process of decline in health and functioning in later life is a multifactorial phenomenon affected by biological changes, physical and social environments, personality, education and lifestyle, along with cultural features and societal policies, many of which are interrelated (e.g. Scarmeas and Stern, 2003; Adam et al., 2007). Some of the detrimental effects of these aspects can be prevented or reduced by societal policies regarding retirement, pensions, taxation, etc. (Rohwedder and Willis, 2010; Rechel et al., 2013), as well as by psycho-social interventions on various societal levels - national, community and personal (Hultsch et al., 1999; Livingston et al., 2017).

Currently, cognitive decline (CD) is one of the major problems faced by ageing societies. The prevalence of CD increases significantly with ageing (WHO, 2017a; Alzheimer's Association, 2018). With the exception of one study (Coe et al., 2012), mandatory retirement and early retirement policies have been repeatedly reported as macro-factors that are negatively associated with people's cognitive functioning (e.g. Adam et al., 2007; Rohwedder and Willis, 2010; Bonsang et al., 2012; Mazzonna and Peracchi, 2012; Fisher et al., 2014; Petersen et al., 2018). For many people, retirement is a significant event causing major changes in routine life, which may accelerate the progression of CD (Bonsang et al., 2012; Mazzonna and Peracchi, 2012). However, two more recent meta-analyses (Meng et al., 2017; Zulka et al., 2019) report conflicting findings regarding the relationship between retirement and CD across large-scale international studies. Such inconsistencies lead to a need for studies directed towards understanding the exact mechanisms which can explain the contradictory relationships between retirement and CD.

One of the explanations for these inconsistencies can be the fact that most of the studies in this area did not include relevant life changes after retirement and their positive or negative influences on CD (e.g. in Rohwedder and Willis, 2010; Zulka et al., 2019). For instance, there are indications that an active lifestyle including leisure activities, cognitive stimulation and physical exercise can moderate and even improve cognitive functioning in later life and after retirement (e.g. Salthouse, 2006; Hertzog et al., 2008; Koepsell and Monsell, 2012; Lifshitz-Vahav et al., 2017). Further research is therefore needed in order to enhance this body of knowledge.

The purpose of this study is to evaluate longitudinal relationships between a series of well-established correlates of CD and memory decline (MD) among retirees living in various European countries. We intend to assess the unique long-term associations of a series of national, personal and behavioural factors with $\mathrm{MD}$, as well as the associations of changes in relevant factors over four years.

\section{$C D$ in old age}

Dementia and depression are the most common mental health diseases in late life (WHO, 2017b). These conditions are often interrelated (Byers and Yaffe, 2011), and both lead to decline in functioning of older adults and in their independence. High levels of incidence and prevalence of dementia diseases are reported globally (Livingston et al., 2017). By the end of 2017, approximately 50 million people worldwide were estimated to have dementia, with an estimated 10 million 
additional people diagnosed with dementia each year (WHO, 2017a). The prevalence of dementia diseases increases sharply with age (Ferri et al., 2005; WHO, 2017a; Petersen et al., 2018). For instance, in North American and European countries, this percentage increases from a range of 1.3-1.7 per cent among people aged 65-69 to a range of 24.5-30.1 per cent among people aged 85 and older (Ferri et al., 2005). Cognitive impairment conditions are especially difficult to cope with (Reisberg et al., 1982; George and Gwyther, 1986) due to the symptoms involved, which include losses in memory, orientation in time and place, personality and communication abilities, and later in the process, also decline in physical functioning, all of which lead to complete dependency (Alzheimer's Association, 2018). The current absence of effective medical means for prevention or cure of dementia diseases intensifies the threat of dementia and the related burden and frustration for all parties involved.

\section{Facets of cognitive impairment in old age}

Cognitive impairment is assessed based on various dimensions such as memory, fluency, reasoning, executive functioning, numeric abilities, speed of processing, etc. (Salthouse, 1985; Banks and Mazzonna, 2012; Nyberg et al., 2012). Our study focuses only on the weakening of memory, which is one of the earliest symptoms to be recognised as a sign of decline in cognitive functioning. This symptom is often overlooked because the onset of forgetfulness is gradual (WHO, 2017a), begins rather early in life (Schaie, 1989) and is often perceived as a part of normal ageing. In the last century, various types of memory have been studied, including primary, procedural, semantic and declarative (e.g. Tulving, 1995). One of the main distinctions in memory types is between episodic memory referring to longterm memory of experienced events that can be located in time and space, and working memory defined as the temporary maintenance, storage and updating of representations. Weakening in both types of memory begins around age 60 and continues to worsen with age (Nyberg et al., 2012).

A diagnosis of mild decline in a number of cognitive functions including memory and orientation in time and/or familiar places is called Mild Cognitive Impairment (MCI) (WHO, 2017a). The prevalence of MCI increases with age, starting with 6.7 per cent among the young-old (aged 60-64) and escalating to more than 25 per cent in the age range of 80-84 (Petersen et al., 2018). People diagnosed with $\mathrm{MCI}$ are at increased risk of developing dementia diseases over a relatively short period in comparison to people in the same age group who are not diagnosed with MCI (Roberts and Knopman, 2013; Petersen et al., 2018). However, people with MCI may benefit from interventions such as cognitive training and physical exercise, which can slow the pace of further decline and, in some cases, even improve the clinical expression of cognitive impairment (Koepsell and Monsell, 2012; Livingston et al., 2017). For this reason, early diagnosis of MCI is important.

\section{National and personal factors related to $C D$}

National policies and cultural aspects play an important role in decisions that may appear to be purely related to personal choice. Mandatory retirement and benefits provided to early retirees are good examples of macro factors influencing personal choices. Considering that retirement accelerates decline in cognitive functioning, 
early retirement causes this degenerative process to commence even earlier (Rohwedder and Willis, 2010; Bonsang et al., 2012). Furthermore, according to Rohwedder and Willis (2010), CD may even begin when people are still on the job-known as 'on-the-job retirement'. This happens because awareness of approaching retirement causes workers to stop investing in work-related training and developmental activities. Study results indicate that the largest drop in CD occurs with retirement (Bonsang et al., 2012), and that delaying retirement by one year is associated with a 3.1 per cent lower risk of dementia even when adjusting for potential confounders (Dufouil et al., 2014). These findings, along with the indication that $\mathrm{CD}$ increases the longer people are in retirement (Mazzonna and Peracchi, 2012), lead to the conclusion that national encouragement to delay retirement for as long as possible has the potential to postpone CD among elderly persons (Rohwedder and Willis, 2010). However, longitudinal comparisons among countries on these issues are lacking (Mazzonna and Peracchi, 2012).

An additional factor which exemplifies a country's influence on personal choices is the educational system. For instance, Banks and Mazzonna (2012) report that the reform in England of adding one year of mandatory education resulted in improved cognitive functioning years later, especially among less-educated men. The positive roles of education and occupational attainment in the preservation of cognitive functioning endure even after retirement (Scarmeas and Stern, 2003; Banks and Mazzonna, 2012; Mazzonna and Peracchi, 2012, 2017; Stern, 2012; Fisher et al., 2014; Ihle et al., 2016). Stern (2012) suggests that higher levels of education and lifelong experience in occupational attainments and/or intensive leisure activities provide a greater cognitive reserve, which in turn increases tolerance to pathology and enables ageing people to be more resilient to degenerative brain changes. Such reserves delay or mask the clinical appearance of dementia symptoms. Thus, people with higher levels of education and intellectually stimulating cognitive activities such as those in higher levels of occupation prior to retirement, suffer from greater underlying disease pathology (Meng and D'Arcy, 2012), and a steeper level of CD, in comparison to people with less cognitive reserve (Stern, 2012).

Regarding physical and mental health, studies show that changes in mood, exposure to difficult life events or acute physical conditions have been reported as causes of temporary and reversible CD (e.g. Fong et al., 2009). More severe and enduring decline in cognitive performance has been found to correlate with decline in objectively evaluated physical health (Livingston et al., 2017; Ihle et al., 2018), self-perceived health, the presence of stress, chronic psychological distress and behavioural disorders such as apnea (e.g. Petersen et al., 2014), as well as more severe conditions including various chronic diseases and comorbidity with its related polypharmacy (De Ronchi et al., 2007; Livingston et al., 2017; Alzheimer's Association, 2018; Mangin et al., 2018). In some studies, a causal relationship has been demonstrated between emotional disorders and cognitive performance. For instance, depression was reported as a risk factor, prodromal and accompanying symptom of CD (Paterniti et al., 2002; Dotson et al., 2010) and Alzheimer's dementia (Enache et al., 2011).

Concerning demographic characteristics, as presented above, the most conspicuous relationship is reported between age and the process of ageing and CD, while inconsistent findings are reported for the association between gender and CD (e.g. Petersen et al., 2014; Ding et al., 2015). 


\section{National differences in cognitive functioning}

Countries differ in reported incidence and prevalence of MCI (Rohwedder and Willis, 2010; Roberts and Knopman, 2013), as well as in the prevalence of various types of CD. For instance, an analysis of data from the Survey of Health, Ageing and Retirement in Europe (SHARE) indicates that except for orientation in time, people living in Mediterranean countries have lower scores in all cognitive domains (Mazzonna and Peracchi, 2012). The reasons for such differences may derive from the multiplicity of cultural, national and personal factors affecting $\mathrm{CD}$. On the national level, factors such as employment, pension and taxation policies, political conditions, health and education systems, cultural perception such as preference for active or inactive lifestyle, and nutrition habits following retirement may be associated with patterns of behaviour which in turn influence cognitive functioning. For instance, although active lifestyle is associated with lower risk for CD, people in Southern European countries have opposite perceptions regarding leading an active lifestyle after retirement compared to people in Northern countries (Börsch-Supan et al., 2008). Knowledge about the effects of such cultural aspects on $\mathrm{CD}$ following retirement is limited and needs to be expanded upon.

On the personal level, national variability in cognitive functioning may be explained by genetics, physical and mental health status, subjective wellbeing and health-related lifestyle - including level of involvement in physical, intellectual and social activities. For instance, lower estimates of MCI prevalence in Finland and Germany compared to the USA on comparable measures (Ward et al., 2012) can be explained by various interactions among the national characteristics related to $\mathrm{CD}$ in old age (retirement policies, education systems and other relevant policies), as well as genetic and lifestyle-related cultural features.

The diversity in incidence and prevalence of MCI among countries may also derive from methodological aspects such as lack of agreement on terminology of MCI (Ward et al., 2012), differences in the criteria used for diagnosing MCI, and in research methods including variability in study designs, samples and statistical analyses of specific age groups (Roberts and Knopman, 2013).

Previous international comparisons of $\mathrm{CD}$ determinants focused mainly on national regulations governing mandatory retirement policies, pension eligibility rules, taxation, and economic characteristics such as income, consumption and wealth, job characteristics and educational systems (e.g. Adam et al., 2007; Börsch-Supan et al., 2008; Rohwedder and Willis, 2010; Banks and Mazzonna, 2012; Bonsang et al., 2012; Fisher et al., 2014; Mazzonna and Peracchi, 2017). Less attention has been paid to the effects of health systems and cultural and health-related behaviours on $\mathrm{CD}$, as well as to the interactions among these factors (Börsch-Supan et al., 2008; Winblad et al., 2016).

Based on the previous reports' findings regarding associations between retirement and $\mathrm{CD}$, and related explanative theories such as 'cognitive reserve', 'use it or lose it' or 'on-the-job retirement', as well as the rather scarce literature on factors attenuating $\mathrm{CD}$, our study aims to simultaneously assess the unique longitudinal contribution of early retirement and a series of established personal and national policy characteristics to the explanation of changes in $\mathrm{MD}$ over a relatively short period (four years) among European retirees living in various countries. Specifically, we hypothesised 
that among retirees, the explanatory power of early retirement as a factor associated with memory change after four years would remain statistically significant even when controlling for indicators of physical and mental health, lifestyle, socio-demographic characteristics, time since retirement, reason for retirement and the changes in these factors over four years, as well as national affiliation. We also hypothesised that in these multivariate analyses the explanatory power of early retirement would differ among retirees living in groups of nations which vary in their welfare regimes, but would remain powerful in each of these groups and add to the explanation of MD.

\section{Method}

\section{Participants and procedures}

For this study we used the SHARE database. SHARE is a multi-disciplinary, crossnational bank of survey data on health, psycho-social and economic variables gathered in several waves (Börsch-Supan et al., 2013).

The current study is based on data from two interviews collected at approximately four-year intervals. For the 12 European countries included in this study (Austria, Germany, Sweden, Netherlands, Spain, Italy, France, Denmark, Switzerland, Belgium, Czech Republic, Poland), we used data from Wave 2 (Time 1 (T1) in our study-gathered during 2006-2007) and from Wave 4 (Time 2 (T2) in our study - collected in 2011). For Israel, we used data from Wave 1 (T1 - collected during 2005-2006) and from Wave 2 (T2-2009-2010). This enabled us to estimate longitudinal relationships between variables evaluated at baseline and $\mathrm{MD}$, as well as changes over a four-year period in some of the relevant variables and $\mathrm{MD}$. Our sample was comprised of 11,930 persons aged 50+ who were retirees at $\mathrm{T} 1$ and were interviewed again four years later.

\section{Measures}

Memory change: number of recalled words

In each of the SHARE waves a list of ten words was read to the participants, who were asked to immediately repeat all of the words that they remembered. Next, they were asked some questions on other topics following which they were asked to repeat the previously presented words that they still remembered. The final score of recalled words was the sum of the number of words remembered both times, ranging from 0 (no words remembered) to 20 (all words remembered). A more detailed explanation regarding the methodological aspects of measuring cognitive ability using the SHARE data is provided by Börsch-Supan et al. (2008). Our dependent variable was calculated as the change in the recalled words from $\mathrm{T} 1$ to $\mathrm{T} 2$. The scale for this variable ranged from -20 indicating that the participant did not remember any of the words at T1, but remembered them all at T2 (= maximal cognitive gain), 0 denoting that the participant remembered the same number of words at both times (no change) and +20 denoting that the participant remembered all of the words at $\mathrm{T} 1$ and none at $\mathrm{T} 2(=$ maximal $\mathrm{CD})$.

\section{Socio-demographic characteristics}

Data were collected on age, gender, education (years of schooling), early retirement from the labour force, years from retirement at T1 and job before retirement. Early 
retirement was constructed as a dichotomous variable. First, age of retirement was calculated based on the reported date of retirement and date of birth. This actual retirement age was then compared to the official retirement age in the participant's country in the year that the person retired. The final dummy variable was constructed as 0 when the participant retired on time or belatedly, according to the official retirement age, or 1 when he or she retired early (Litwin and Tur-Sinai, 2015). Years from retirement were estimated by the years that passed since the participant retired from the labour force until T1. Job before retirement was constructed as a dichotomous variable: 0 when the participant was considered a blue-collar worker such as a skilled agricultural or fishery worker, craft and related trades worker, plant and machine operator or assembler, elementary occupation, etc., and 1 when the participant engaged in a white-collar job such as a legislator, senior official or manager, professional, technician or associate professional, clerk, service worker, shop and market sales worker, etc.

\section{Physical and mental health status}

Health variables at T1 included self-rated health on a 1-5 scale (ranging from 1 excellent to 5 poor); disability in activities of daily living (ADL) was assessed by the number of reported difficulties with getting dressed, bathing, ambulating at home, eating, sitting down and standing up, and using the bathroom; instrumental activities of daily living (IADL) were assessed by the number of reported difficulties with performing daily tasks related to maintaining an independent lifestyle, this includes difficulty with preparing hot meals, shopping for groceries, making telephone calls, taking medications, doing work around the house or garden and managing money; depressive symptoms were evaluated by the EURO-D scale-a validated measure of depression, which is based on assessments of 12 self-reported depressive symptoms such as trouble sleeping, irritability, appetite, fatigue and ability to concentrate. The scale ranges from 0 to 12 (Prince et al., 1999).

\section{Active lifestyle}

Active lifestyle was assessed by the number of reported activities from a list including volunteer labour, charitable activity, in-service or training activity, involvement in sports clubs, social clubs or some other club, religious organisations, or some political or community activity; post-retirement employment was assessed based on responses to a question asking about the participant's employment status at T2 (scored as 0 for not being employed and 1 for being employed); reason for retirement was assessed based on responses to the question: 'for which reasons did you retire?' Responses to this question received one of three scores: 0 for retirement due to structural reasons (e.g. becoming eligible for public pension, private occupational pension or private pension, having been offered an early retirement option/window with special incentives, or being made redundant); 1 for retirement due to health reasons (retiring because of one's own ill health, or the ill health of a relative or friend); 2 for both structural and health reasons (at least one of the structural reasons in addition to at least one of the health reasons). The list of response options also included wishes to retire at the same time as a spouse, spend more time with family and to enjoy life. Because only 61 participants reported any of these last three reasons, we did not include them in our analyses. 


\section{Country/region}

The 13 countries included in the SHARE data were divided into four geographical regions according to classification based on groupings of countries with similar socio-economic regimes (Antonova et al., 2015): Eastern (Czech Republic, Poland), Central (Austria, Germany, France, Switzerland, Belgium), Northern (Sweden, Netherlands, Denmark) and Mediterranean (Spain, Italy, Israel).

\section{Changes in physical and mental health and functioning}

Changes were assessed based on responses to the same questions at T1 and T2. The potential scale for change in self-rated health ranged from -5 to +5 , for change in $A D L$ from -6 to +6 ; for change in IADL the scale ranged from -7 to +7 ; for change in depressive symptom the scale ranged from -12 to +12 . The negative scores denoted improvement in health/function at T2, 0 denoted no change, and positive scores denoted decline in health and/or function.

\section{Changes in active lifestyle}

Changes were assessed based on responses at T1 and T2 to the same question regarding number of various activities. The potential scale for changes in active lifestyle ranged from -7 to +7 : negative scores denoting engagement in more activities at T2, 0 denoting no change and positive scores denoting engagement in less activities at $\mathrm{T} 2$.

\section{Data analysis methods}

Univariate associations between MD - the dependent variable - and the independent explanatory variables were examined using Pearson, Spearman or chi-square tests. Hierarchical multivariate linear regression analyses were performed to explain changes in memory over the four-year period. In the first ordinary least squares model, the change in memory was analysed as a function of the series of explanatory variables assessed at $\mathrm{T} 1$, and the changes that occurred in them between $\mathrm{T} 1$ and T2. To the second model, we added the variables of active lifestyle after retirement, change in active lifestyle and employment. To the third model we added the blocks of countries divided according to welfare regimes and to the fourth model we added interactions between the welfare regimes and early retirement status. Data were analysed using Stata version 15.1 (StataCorp, College Station, TX).

\section{Results}

Descriptive characteristics of the research population at baseline (T1) are presented in Table 1. The average number of words remembered (about nine out of 20) indicates medium or poor retention. More than 87 per cent $(\mathrm{N}=10,379)$ of respondents noted that they had retired from work at or after the official age. Among participants who retired early, the average number of years of potential work lost due to early retirement was 7.3 years (standard deviation $(\mathrm{SD})=4.9$ ). The average age was close to $69(\mathrm{SD}=9.2$, range $=52-84)$ and more than half of the participants were women. The average number of years of education was $11.2(\mathrm{SD}=4.3)$. About 70 per cent of the participants rated their health as 'good', 'very good' or 'excellent', and most participants reported no ADL or IADL limitations. The reported number 
Table 1. Comparison between the study participants (interviewed at Time (T1) and Time (T2)) and those who dropped out of the study at $\mathrm{T} 2$

\begin{tabular}{|c|c|c|c|}
\hline \multirow[b]{2}{*}{ Characteristics at $\mathrm{T} 1$} & \multicolumn{2}{|c|}{ Outcome at T2 } & \multirow[b]{2}{*}{$F / \chi^{2}$} \\
\hline & Study sample & Dropped out & \\
\hline N (\%) & $11,930(73.2)$ & $4,363(26.8)$ & \\
\hline \multicolumn{4}{|l|}{ Dependent variable: } \\
\hline Number of recalled words (SD) & $8.9(3.4)$ & $8.2(3.7)$ & $652.9^{\star \star \star}$ \\
\hline \multicolumn{4}{|l|}{ Independent variables: } \\
\hline \multicolumn{4}{|l|}{ Early retirement (among retired) (\%): } \\
\hline Yes & 12.4 & 21.1 & \multirow[t]{2}{*}{$135.8^{\star * *}$} \\
\hline No & 87.6 & 78.9 & \\
\hline \multicolumn{4}{|l|}{ Socio-demographic: } \\
\hline Mean age in years (SD) & $68.9(9.2)$ & $66.5(10.2)$ & $6.2^{\star \star \star}$ \\
\hline \multicolumn{4}{|l|}{ Gender (\%): } \\
\hline Women & 56.1 & 55.0 & \multirow[t]{2}{*}{$13.6^{\star \star}$} \\
\hline Men & 43.9 & 45.0 & \\
\hline Mean years of education (SD) & $11.2(4.3)$ & $10.3(4.6)$ & $121.2^{\star \star \star}$ \\
\hline \multicolumn{4}{|l|}{ Health: } \\
\hline \multicolumn{4}{|l|}{ Self-perceived health (\%): } \\
\hline Excellent & 10.8 & 8.5 & \multirow[t]{5}{*}{$388.2^{\star \star \star}$} \\
\hline Very good & 20.6 & 19.2 & \\
\hline Good & 38.2 & 34.3 & \\
\hline Medium & 22.9 & 25.6 & \\
\hline Poor & 7.5 & 12.4 & \\
\hline Mean ADL limitations (SD) & $0.1(0.5)$ & $0.3(0.9)$ & $541.6^{\star \star \star}$ \\
\hline Mean IADL limitations (SD) & $0.2(0.8)$ & $0.3(1.2)$ & $160.7^{\star \star \star}$ \\
\hline Mean depressive symptoms (SD) & $2.1(2.1)$ & $2.3(2.4)$ & $18.5^{\star \star \star}$ \\
\hline \multicolumn{4}{|l|}{ Retirement reason (\%): } \\
\hline Structural & 77.2 & 76.9 & \multirow[t]{3}{*}{1.3} \\
\hline Health & 18.6 & 18.8 & \\
\hline Structural and health & 4.2 & 4.3 & \\
\hline Mean years from retirement (SD) & $2.8(2.6)$ & $2.7(2.3)$ & 1.7 \\
\hline \multicolumn{4}{|l|}{ Job before retirement $(\%)$ : } \\
\hline Blue collar & 31.6 & 31.9 & \multirow[t]{2}{*}{0.4} \\
\hline White collar & 68.4 & 68.1 & \\
\hline Mean active lifestyle (SD) & $0.9(1.0)$ & $0.7(0.5)$ & $2.4^{\star}$ \\
\hline
\end{tabular}

Notes: SD: standard deviation. ADL: activities of daily living. IADL: instrumental activities of daily living.

Source: Survey of Health, Ageing and Retirement in Europe (SHARE) - Israel (2005/2006, 2009/2010), Europe (2006/2007, 2011). Significance levels: ${ }^{\star} p<0.05,{ }^{* \star} p<0.01,{ }^{\star \star \star} p<0.001$. 
of depressive symptoms was very low as well. About 77 per cent of the respondents reported that they had retired due to structural reasons, 19 per cent because of health reasons and 4 per cent due to both structural and health reasons. Less than half of the participants reported having an active lifestyle.

A significant number of participants $(4,363)$ dropped out at T2, most of them due to non-response $(81.3 \%)$ and others due to death (18.7\%). In this study, we included data only from the retirees who participated in the study at both T1 and T2. Examination shows that the number of recalled words among those who responded at both times was significantly higher than among the drop-out respondents at T1. Compared to participants who remained in the study, people who dropped out, despite being younger in age, were a weaker group in terms of physical and mental health and functioning, and were less active in their daily lives (Table 1). In addition, among those who participated at both $\mathrm{T} 1$ and $\mathrm{T} 2$, we excluded a relatively small number of people (61) who reported that they retired early in order to spend more time with family, to enjoy life or at the same time as their spouses - categories which had no relevance to health or laws for mandatory retirement.

A comparison among social and geographical regions for the T1 study variables is presented in Table 2 . The average score for memory was significantly higher among retirees who lived in the Northern European bloc of countries in comparison to that of retirees who lived in all other regions, especially in comparison to those who lived in the Mediterranean countries. Regarding early retirement, while 18.5 per cent of participants from Eastern European countries retired before reaching the official retirement age, only around 11 per cent reported early retirement in the other regions. With the exception of age and gender, the comparison among geographical regions revealed significant variance in most sociodemographic characteristics and health factors. While the average education level of participants living in Northern and Central European countries was nearly identical, it was significantly lower among retirees living in Eastern European and Mediterranean countries. Nearly 49 per cent of participants from Eastern European countries and about 35 per cent from Mediterranean countries assessed their state of health as medium or poor, compared to only around 21-26 per cent of participants living in Northern and Central European countries. Accordingly, participants from Eastern European countries also reported a significantly higher number of ADL and IADL limitations compared to participants living in the other European regions. The level of depressive symptoms was also higher among participants living in the Eastern European countries than among those living in Northern Europe.

Regarding reasons for retirement, while 23.5 per cent of participants from Northern countries reported retiring due to health problems, similar reasons were reported only by around 13.9 per cent in Eastern European countries. Retiring for structural reasons was reported by 82.7 per cent of participants from Eastern European countries compared to around 71 per cent in Northern countries. The number of years since retirement was higher among participants living in Mediterranean and Eastern European countries than among participants living in Northern Europe. In all four regions, most of the retirees were employed in white-collar jobs before retirement; a higher proportion of those employed in blue- 
Table 2. Descriptive characteristics (at Time 1) of the sample by blocks of similar nations

\begin{tabular}{|c|c|c|c|c|c|}
\hline & Northern & Central & Mediterranean & Eastern & $F / \chi^{2}$ \\
\hline \multicolumn{6}{|l|}{ Dependent variable: } \\
\hline \multicolumn{6}{|l|}{ Independent variables: } \\
\hline \multicolumn{6}{|c|}{ Early retirement (among retired) (\%): } \\
\hline No & 89.4 & 88.5 & 88.8 & 81.5 & $85.7^{\star \star \star}$ \\
\hline \multicolumn{6}{|l|}{ Socio-demographic: } \\
\hline Mean age in years (SD) & $68.9(9.2)$ & $69.2(9.2)$ & $69.1(9.2)$ & $68.6(8.8)$ & 2.5 \\
\hline \multicolumn{6}{|l|}{ Gender (\%): } \\
\hline Women & 56.6 & 56.9 & 55.2 & 54.8 & 4.7 \\
\hline \multicolumn{6}{|l|}{ Self-perceived health (\%): } \\
\hline Excellent & 18.9 & 9.4 & 9.4 & 2.2 & \multirow[t]{5}{*}{$1,400.3^{\star \star \star}$} \\
\hline Very good & 27.4 & 21.0 & 18.2 & 11.5 & \\
\hline Good & 32.4 & 43.2 & 37.0 & 37.7 & \\
\hline Medium & 18.2 & 21.1 & 26.9 & 29.9 & \\
\hline Poor & 3.1 & 5.3 & 8.5 & 18.7 & \\
\hline
\end{tabular}


Table 2. (Continued.)

\begin{tabular}{|c|c|c|c|c|c|}
\hline & Northern & Central & Mediterranean & Eastern & $F / \chi^{2}$ \\
\hline Mean ADL limitations (SD) & $0.1(0.4)$ & $0.1(0.5)$ & $0.1(0.6)$ & $0.3(0.7)$ & $43.6^{\star \star \star}$ \\
\hline Mean IADL limitation (SD) & $0.1(0.5)$ & $0.2(0.6)$ & $0.2(0.7)$ & $0.4(0.9)$ & $11.5^{\star \star \star}$ \\
\hline Mean depressive symptoms (SD) & $1.7(1.7)$ & $2.1(2.0)$ & $2.3(2.2)$ & $2.7(2.4)$ & $142.5^{\star \star \star}$ \\
\hline \multicolumn{6}{|l|}{ Retirement reason (\%): } \\
\hline Structural & 71.2 & 76.1 & 79.1 & 82.7 & \multirow[t]{3}{*}{$81.5^{\star \star \star}$} \\
\hline Health & 23.5 & 19.6 & 17.4 & 13.9 & \\
\hline Structural and health & 5.3 & 4.3 & 3.5 & 3.4 & \\
\hline Mean years from retirement (SD) & $1.7(1.8)$ & $2.5(2.3)$ & $4.1(3.7)$ & $3.1(2.1)$ & $136.7^{\star \star \star}$ \\
\hline \multicolumn{6}{|l|}{ Job before retirement (\%): } \\
\hline Blue collar & 27.8 & 30.2 & 31.6 & 39.6 & \multirow[t]{2}{*}{$83.1^{\star \star \star}$} \\
\hline White collar & 72.2 & 69.8 & 68.4 & 60.4 & \\
\hline Mean active lifestyle (SD) & $1.4(1.2)$ & $1.1(1.2)$ & $0.6(0.9)$ & $0.4(0.7)$ & $209.4^{\star \star \star}$ \\
\hline
\end{tabular}

Notes: SD: standard deviation. ADL: activities of daily living. IADL: instrumental activities of daily living.

Source: Survey of Health, Ageing and Retirement in Europe (SHARE) - Israel (2005/2006, 2009/2010), Europe (2006/2007, 2011).

Significance levels: ${ }^{\star} p<0.05,{ }^{\star \star} p<0.01,{ }^{\star \star \star} p<0.001$. 


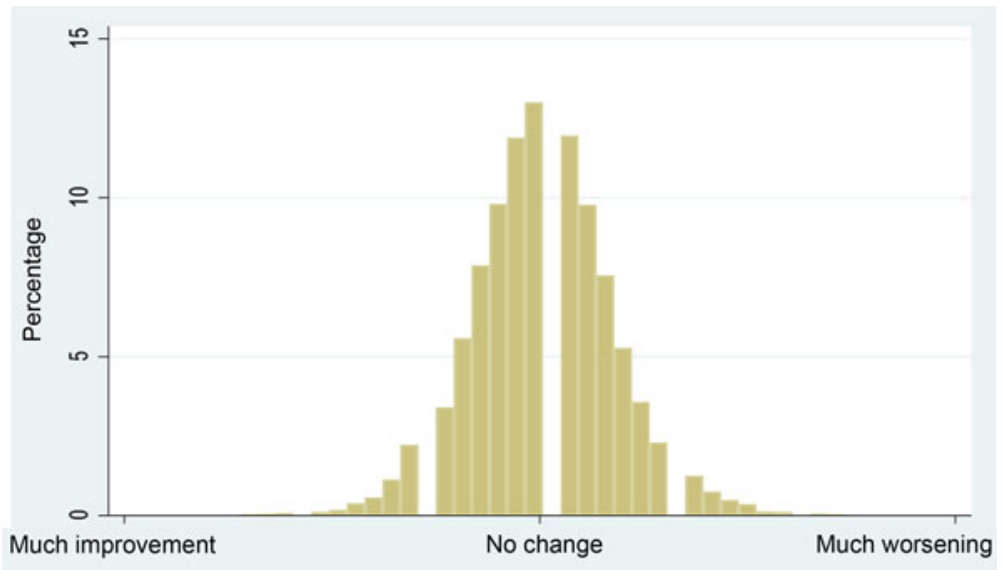

Figure 1. Distribution of change in memory during the four years of the study among retirees. Source: Survey of Health, Ageing and Retirement in Europe (SHARE) - Israel (2005/2006, 2009/2010), Europe (2006/ 2007, 2011).

collar jobs before retirement were from Eastern European countries. The average score for leading an active lifestyle was higher among the participants from Northern Europe and lower among the participants from Eastern Europe.

Turning to the dynamic aspects of the study, the distribution of the memory change variable was found to be close to normal, with an average score of -0.052 $(\mathrm{SD}=3.45)$ and a median of 0 (see Figure 1). Over the years, a stable level of memory was found among only 13 per cent of the participants, whereas the proportion of participants whose memory improved (about $43 \%$ ) was found to be almost identical (44\%) to that of participants with MD (Table 3). The distributions of the changes in the study variables show that they are centred to the mean (see Figure 2).

Around 32 per cent of participants reported deterioration in their self-rated health, while 23 per cent reported an improvement. Deterioration in ADL was found among 8.6 per cent and improvement in ADL among 5 per cent of participants. Deterioration in IADL was found among 13.1 per cent of participants and improvement in IADL was found among 6.2 per cent of participants. Depressive symptoms worsened among 40 per cent of the participants but improvement was reported by 35 per cent of them. About 25 per cent of participants in all regions reported that they returned to the labour force over the years and 43.5 per cent reported improvement in active lifestyle (Table 3).

A comparison among the geographical regions of European countries showed an inter-regional variance. The Northern countries were typified by the highest percentage of participants who reported decline in their memory over time, whereas the percentage of those who reported improvement in memory was found to be highest in Central European countries. This is probably because the average score of recalled words at baseline was highest in Northern nations. However, the ratio of participants who noted deterioration in ADL or in IADL was lowest in Northern countries and highest in Eastern European countries. The highest percentage of improvement in active lifestyle was reported in Eastern nations (61.8\%) 
Table 3. Changes in the study variables between Time 1 and Time 2 (T2)

\begin{tabular}{|c|c|c|c|c|c|c|}
\hline & \multicolumn{5}{|c|}{ Geographical region } & \multirow[b]{2}{*}{$F / \chi^{2}$} \\
\hline & All & Northern & Central & Mediterranean & Eastern & \\
\hline & \multicolumn{5}{|c|}{ Percentages } & \\
\hline \multicolumn{7}{|l|}{ Health (change): } \\
\hline \multicolumn{7}{|c|}{ Number of recalled words: } \\
\hline Improvement & 43.3 & 39.3 & 46.6 & 44.2 & 41.3 & \multirow[t]{3}{*}{$64.6^{\star \star \star}$} \\
\hline No change & 13.0 & 13.4 & 13.1 & 12.6 & 12.8 & \\
\hline Deterioration & 43.7 & 47.3 & 40.3 & 43.2 & 45.9 & \\
\hline \multicolumn{7}{|c|}{ Self-perceived health: } \\
\hline Improvement & 22.5 & 23.6 & 20.5 & 22.0 & 26.2 & \multirow[t]{3}{*}{$169.9^{\star \star \star}$} \\
\hline No change & 45.8 & 43.2 & 47.6 & 45.1 & 47.1 & \\
\hline Deterioration & 31.7 & 33.2 & 31.9 & 32.9 & 26.7 & \\
\hline \multicolumn{7}{|l|}{ ADL problems: } \\
\hline Improvement & 4.6 & 3.3 & 4.6 & 3.8 & 8.3 & \multirow[t]{3}{*}{$287.6^{\star \star \star}$} \\
\hline No change & 86.8 & 90.6 & 85.8 & 88.2 & 80.6 & \\
\hline Deterioration & 8.6 & 6.1 & 9.6 & 8.0 & 11.1 & \\
\hline \multicolumn{7}{|l|}{ IADL problems: } \\
\hline Improvement & 6.2 & 4.4 & 5.5 & 6.1 & 11.0 & \multirow[t]{3}{*}{$328.5^{\star \star \star}$} \\
\hline No change & 80.7 & 85.6 & 82.1 & 78.6 & 71.9 & \\
\hline Deterioration & 13.1 & 10.0 & 12.4 & 15.3 & 17.1 & \\
\hline
\end{tabular}




\begin{tabular}{|c|c|c|c|c|c|c|}
\hline Depressive symp & & & & & & \\
\hline Improvement & 34.7 & 33.2 & 32.6 & 37.4 & 38.6 & \multirow[t]{3}{*}{$324.5^{\star \star \star}$} \\
\hline No change & 25.2 & 29.5 & 24.4 & 23.8 & 21.5 & \\
\hline Deterioration & 40.1 & 37.3 & 43.0 & 38.8 & 39.9 & \\
\hline \multicolumn{7}{|l|}{ Active lifestyle: } \\
\hline Improvement & 43.5 & 37.3 & 45.0 & 35.5 & 61.8 & \multirow[t]{3}{*}{$805.1^{\star \star \star}$} \\
\hline No change & 53.4 & 61.8 & 53.0 & 56.9 & 35.2 & \\
\hline Deterioration & 3.1 & 0.9 & 2.0 & 7.6 & 3.0 & \\
\hline \multicolumn{7}{|c|}{ Employment (at T2): } \\
\hline Yes & 25.5 & 31.7 & 23.7 & 27.9 & 15.3 & \multirow[t]{2}{*}{$241.5^{\star \star \star}$} \\
\hline No & 74.5 & 68.3 & 76.3 & 72.1 & 84.7 & \\
\hline
\end{tabular}

Notes: ADL: activities of daily living. IADL: instrumental activities of daily living.

Source: Survey of Health, Ageing and Retirement in Europe (SHARE) - Israel (2005/2006, 2009/2010), Europe (2006/2007, 2011)

Significance level: ${ }^{\star \star \star} p<0.001$. 

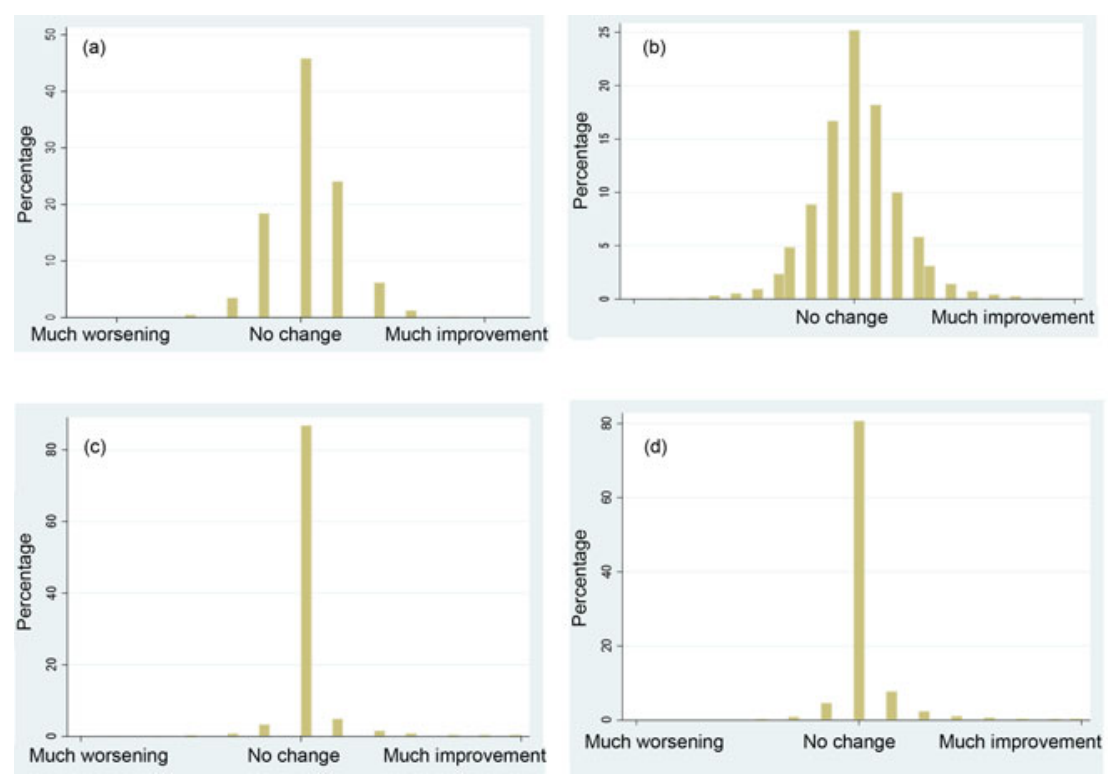

Figure 2. Changes in study variables between Time 1 and Time 2. (a) Self-perceived health change; (b) depressive symptoms change; (c) activities of daily living change; (d) instrumental activities of daily living change.

and the lowest in Mediterranean countries (35.5\%). Daily involvement in sports or social clubs, and volunteering were the most frequently reported activities (16.7 and $16.6 \%$, respectively). The ratio of participants who retired but returned to work was found to be lowest (15.3\%) in Eastern European countries and highest (31.7\%) in the Northern countries.

Univariate analyses between the independent variables and memory change showed that except for gender, all of the study variables significantly correlated with memory change (MC). More specifically, a significantly greater MD was found among participants who reported early retirement along with lack of active lifestyle or who reported stopping their active lifestyle at T2, while returning to employment after retirement correlated with decreases in MD. Participants who reported that their reason for retirement was related to health problems were found to have a significantly greater decline in memory compared to participants who retired due to structural reasons. Poor physical and mental health variables and the declines in them after four years correlated significantly with MD, so that the worse the reported health and function (self-rated health, ADL and IADL) at T1, and the greater the decline in them, as well as the increase in depressive symptoms, the greater also the decline in memory.

Hierarchical regression models were constructed to assess the unique contribution of each of the study variables, including changes in some of them over the four years of the study (changes in active lifestyle, employment, and physical and mental health), to the explanation of change in the number of remembered words between T1 and T2 (Table 4). 
Table 4. Ordinary least squares regression models explaining memory change in number of recalled words between Time 1 (T1) and Time 2 (T2)

\begin{tabular}{|c|c|c|c|c|}
\hline & Model 1 & Model 2 & Model 3 & Model 4 \\
\hline \multicolumn{5}{|c|}{$\beta$ values (standard errors) } \\
\hline \multirow[t]{2}{*}{ Total words (T1) } & $0.564^{\star \star \star}$ & $0.572^{\star \star \star}$ & $0.579^{\star \star \star}$ & $0.583^{\star \star \star}$ \\
\hline & $(0.01)$ & $(0.01)$ & $(0.01)$ & $(0.01)$ \\
\hline \multirow[t]{2}{*}{ Gender $^{1}$} & 0.007 & 0.006 & 0.005 & 0.006 \\
\hline & $(0.07)$ & $(0.07)$ & $(0.07)$ & $(0.07)$ \\
\hline \multirow[t]{2}{*}{$\mathrm{Age}^{2}$} & $0.192^{\star \star \star}$ & $0.193^{\star \star \star}$ & $0.207^{\star \star \star}$ & $0.210^{\star * *}$ \\
\hline & $(0.05)$ & $(0.05)$ & $(0.01)$ & $(0.01)$ \\
\hline \multirow[t]{2}{*}{ Education } & $-0.148^{\star \star \star}$ & $-0.136^{\star \star \star}$ & $-0.127^{\star \star \star}$ & $-0.124^{\star \star \star}$ \\
\hline & $(0.08)$ & $(0.09)$ & $(0.01)$ & $(0.01)$ \\
\hline \multirow[t]{2}{*}{ Self-perceived health } & $0.081^{\star \star \star}$ & $0.052^{\star \star \star}$ & $0.060^{\star \star \star}$ & $0.059^{\star * *}$ \\
\hline & $(0.05)$ & $(0.05)$ & $(0.04)$ & $(0.05)$ \\
\hline \multirow{2}{*}{$\begin{array}{l}\text { Self-perceived health } \\
\text { (change) }\end{array}$} & $0.057^{\star \star \star}$ & $0.052^{\star \star \star}$ & $0.049^{\star \star \star}$ & $0.046^{\star \star \star}$ \\
\hline & $(0.04)$ & $(0.04)$ & $(0.04)$ & $(0.04)$ \\
\hline \multirow[t]{2}{*}{ ADL problems } & 0.014 & 0.012 & 0.011 & 0.010 \\
\hline & $(0.08)$ & $(0.08)$ & $(0.07)$ & $(0.08)$ \\
\hline \multirow{2}{*}{$\begin{array}{l}\text { ADL problems } \\
\text { (change) }\end{array}$} & 0.011 & 0.009 & 0.013 & 0.012 \\
\hline & $(0.05)$ & $(0.05)$ & $(0.05)$ & $(0.05)$ \\
\hline \multirow[t]{2}{*}{ IADL problems } & $0.079^{\star \star \star}$ & $0.070^{\star \star \star}$ & $0.067^{\star \star \star}$ & $0.068^{\star \star}$ \\
\hline & $(0.06)$ & $(0.06)$ & $(0.06)$ & $(0.06)$ \\
\hline \multirow{2}{*}{$\begin{array}{l}\text { IADL problems } \\
\text { (change) }\end{array}$} & $0.109^{\star * \star}$ & $0.100^{\star \star \star}$ & $0.098^{\star \star \star}$ & $0.097^{\star \star \star}$ \\
\hline & $(0.04)$ & $(0.04)$ & $(0.04)$ & $(0.04)$ \\
\hline \multirow[t]{2}{*}{ Depressive symptoms } & $0.053^{\star \star \star}$ & $0.052^{\star \star \star}$ & $0.052^{\star \star \star}$ & $0.046^{\star \star}$ \\
\hline & $(0.02)$ & $(0.02)$ & $(0.02)$ & $(0.02)$ \\
\hline \multirow{2}{*}{$\begin{array}{l}\text { Depressive symptoms } \\
\text { (change) }\end{array}$} & $0.080^{\star \star \star}$ & $0.077^{\star \star \star}$ & $0.077^{\star \star \star}$ & $0.075^{\star \star \star}$ \\
\hline & $(0.02)$ & $(0.02)$ & $(0.02)$ & $(0.02)$ \\
\hline Retirement reason: ${ }^{3}$ & $0.013^{\star \star}$ & $0.013^{\star \star}$ & $0.011^{\star \star}$ & $0.010^{\star \star}$ \\
\hline Health & $(0.05)$ & $(0.06)$ & $(0.06)$ & $(0.05)$ \\
\hline Structural & $0.011^{\star \star}$ & $0.009^{\star \star}$ & $0.009^{\star \star}$ & $0.007^{\star \star}$ \\
\hline $\begin{array}{l}\text { Structural and } \\
\text { health }\end{array}$ & $(0.06)$ & $(0.05)$ & $(0.07)$ & $(0.05)$ \\
\hline \multirow[t]{2}{*}{ Early retirement } & $0.048^{\star \star \star}$ & $0.048^{\star \star \star}$ & $0.045^{\star \star \star}$ & \\
\hline & $(0.12)$ & $(0.12)$ & $(0.12)$ & \\
\hline \multirow[t]{2}{*}{ Years from retirement } & $0.023^{\star \star}$ & $0.021^{\star \star}$ & $0.020^{\star \star}$ & $0.020^{\star \star}$ \\
\hline & $(0.08)$ & $(0.08)$ & $(0.07)$ & $(0.07)$ \\
\hline
\end{tabular}


Table 4. (Continued.)

\begin{tabular}{|c|c|c|c|c|}
\hline & Model 1 & Model 2 & Model 3 & Model 4 \\
\hline \multirow{2}{*}{$\begin{array}{l}\text { Job before } \\
\text { retirement }^{4}\end{array}$} & $-0.005^{\star}$ & $-0.005^{\star}$ & $-0.004^{\star}$ & $-0.004^{\star}$ \\
\hline & $(0.003)$ & $(0.003)$ & $(0.003)$ & $(0.003)$ \\
\hline \multirow[t]{2}{*}{ Active lifestyle } & & $-0.085^{\star \star \star}$ & $-0.068^{\star \star \star}$ & $-0.107^{\star \star \star}$ \\
\hline & & $(0.04)$ & $(0.12)$ & $(0.12)$ \\
\hline \multirow{2}{*}{$\begin{array}{l}\text { Active lifestyle } \\
\text { (change) }\end{array}$} & & $0.053^{\star \star \star}$ & $0.042^{\star \star \star}$ & $0.089^{\star \star \star}$ \\
\hline & & $(0.08)$ & $(0.10)$ & $(0.10)$ \\
\hline \multirow[t]{2}{*}{ Employment } & & $-0.09^{\star \star \star}$ & $-0.007^{\star \star \star}$ & $-0.007^{\star \star \star}$ \\
\hline & & $(0.05)$ & $(0.05)$ & $(0.05)$ \\
\hline Mediterranean region & & & Ref. & Ref. \\
\hline \multirow[t]{2}{*}{ Eastern region } & & & -0.001 & -0.013 \\
\hline & & & $(0.11)$ & $(0.12)$ \\
\hline \multirow[t]{2}{*}{ Central region } & & & $-0.075^{\star \star \star}$ & $-0.073^{\star \star \star}$ \\
\hline & & & $(0.10)$ & $(0.11)$ \\
\hline \multirow[t]{2}{*}{ Northern region } & & & $-0.044^{\star \star}$ & $-0.036^{\star \star}$ \\
\hline & & & $(0.12)$ & $(0.12)$ \\
\hline \multirow{2}{*}{$\begin{array}{l}\text { Mediterranean } \\
\text { region } \times \text { Early } \\
\text { retirement }\end{array}$} & & & & $0.017^{\star \star}$ \\
\hline & & & & $(0.14)$ \\
\hline \multirow{2}{*}{$\begin{array}{l}\text { Eastern region } \times \text { Early } \\
\text { retirement }\end{array}$} & & & & $0.038^{\star \star \star}$ \\
\hline & & & & $(0.21)$ \\
\hline \multirow{2}{*}{$\begin{array}{l}\text { Central region } \times \text { Early } \\
\text { retirement }\end{array}$} & & & & $0.025^{\star \star \star}$ \\
\hline & & & & $(0.16)$ \\
\hline \multirow{2}{*}{$\begin{array}{l}\text { Northern region } \times \\
\text { Early retirement }\end{array}$} & & & & $0.004^{\star}$ \\
\hline & & & & $(0.10)$ \\
\hline Adjusted $R^{2}$ & 0.2867 & 0.2913 & 0.2972 & 0.2991 \\
\hline $\mathrm{N}$ & 11,516 & 10,231 & 10,231 & 10,231 \\
\hline
\end{tabular}

Notes: The dependent variable is the change in memory (number of recalled words) between T1 and T2. Higher score represents a decline in memory. Higher score in each health variable (including the change variables) represents a poorer condition. 1 . Gender: $1=$ male, $0=$ female. 2 . Aged $50+$ at T1. 3. Retirement reason: $0=$ structural reason, $1=$ health reason, $2=$ structural and health reasons. 4 . Job before retirement: $0=$ blue collar, $1=$ white collar. ADL: activities of daily living. IADL: instrumental activities of daily living. Ref.: reference category.

Source: Survey of Health, Ageing and Retirement in Europe (SHARE) - Israel (2005/2006, 2009/2010), Europe (2006/2007, 2011).

Significance levels: ${ }^{\star} p<0.05,{ }^{\star \star} p<0.01,{ }^{\star \star \star} p<0.001$.

The results of the regression analyses (Model 1) indicate that the higher the number of words recalled at $\mathrm{T} 1$, the greater the MD at $\mathrm{T} 2(\beta=0.564)$. While gender was not related to memory change over time, we found that memory declined with age $(\beta=0.192)$ but improved the higher the participants' level of education was 
( $\beta=-0.148)$. Regarding health and function, the poorer the reported health was at T1, the greater the MD was over time $(\beta=0.081)$. Similarly, decline in self-rated health over time correlated with MD over time $(\beta=0.057)$. The more IADL limitations a person had at T1, the greater the MD at T2 $(\beta=0.079)$. Increase in IADL limitations over time was also related to decline in memory $(\beta=0.109)$. The higher the reported number of depressive symptoms at T1, the greater the MD at T2 $(\beta=$ $0.053)$. Consistently, the worse a person's depression was after four years, the greater the memory loss $(\beta=0.080)$. MD was higher among participants who reported retiring due to health issues or because of a combination of health and structural reasons. Although we controlled for all of the above-mentioned personal variables, as well as the changes in them over time, MD was greater among participants who reported early retirement at baseline $(\beta=0.048)$. The higher the number of years from retirement at T1, the greater the MD at T2 $(\beta=0.023)$. Finally, MD was higher among participants who were employed in blue-collar jobs than among those who were employed in white-collar jobs before retirement $(\beta=-0.005)$ (Table 4, Model 1). In the second regression equation we added the variables of active lifestyle, change in active lifestyle and employment after retirement from the labour force (Table 4, Model 2). Our results also indicate that compared to active retirees, participants who were not active in their daily lives (such as in volunteering, charitable service, in-service or training activities, physical exercise, social activities, religious or political organisation, or other community activities) or whose number of fields of activities decreased during the four years of the study (at T2) reported greater MD ( $\beta=-0.085$ and $\beta=0.053$, respectively). Participants who chose to return to the labour force after retirement suffered from less MD over time $(\beta=-0.009)$. Model 3 examines the contribution of living in a certain group of countries, beyond the contributions of all of the other personal variables. In contrast to the previous finding based on a univariate comparison of all retirees in the four European regions (Table 3), which indicated that MD was greatest in Northern countries, this model shows that when early retirement is controlled for, the degree of MD over time is lower among retirees living in the Central or Northern regions compared to retirees living in the Mediterranean region of Europe $(\beta=-0.075$ and $\beta=-0.044$, respectively). Finally, in order to assess whether geographic region of residence has a specific contribution to MD among early retirees compared to people who retired at or after the official retirement age, we added an interaction variable between region of residence and early retirement. Since this variable captures all possibilities of early retirement, it should not be generalised together with the 'early retirement' variable; therefore, we removed the latter variable from the frame of estimation in the model. Model 4 shows that in all the geographical regions the tendency for MD over time is stronger among participants who reported early retirement in comparison to participants who retired on time or later. It should be noted that although the increase in the explained variability in Models 3 and 4 is quite low, the unique contributions of the additional variables are statistically significant.

\section{Discussion}

This study was designed to evaluate determinants of MD after four years among European and Israeli retirees by simultaneously assessing the explanatory power 
of a relatively wide series of personal and nation-related characteristics evaluated at baseline (socio-demographic, physical and mental health, active lifestyle, early retirement, reason for retirement, time passed from retirement and national social policy/geographical region), as well as the explanatory power of changes in active lifestyle, and physical and mental health four years after retirement.

Our results lend support to some of the previous studies by showing that in general, gender is not related to MD. For instance, although our findings refer only to $\mathrm{MD}$, no significant gender difference has been found in the prevalence or incidence of Alzheimer's disease, which is the most prevalent dementia disease in old age (Hebert et al., 2001). Also, similar to previous reports (e.g. Spaniol et al., 2006; Nyberg et al., 2012), we found that 'working memory' does decline with ageing among retirees aged 50 years and older. After a follow-up of only four years, a significant decline in working memory occured among about 44 per cent of European retirees, which indicates that in our range of ages (52-84), this process occurs quite rapidly and supports previous findings regarding retirees (e.g. Mazzonna and Peracchi, 2012, 2017). However, we also found a significant percentage of retirees whose memory had improved over time (43\%), along with improvements in health and depressive symptoms (among about 32 and 35\%, respectively). This raises the importance of studying the factors that contribute to both the decline and the improvement in memory over time, factors which may not always be the same. For instance, while $\mathrm{CD}$ can occur following retirement (Rohwedder and Willis, 2010; Bonsang et al., 2012), improvements can derive from interventions directed towards enhancing specific areas of functioning, such as cognitive exercise (e.g. Koepsell and Monsell, 2012; Livingston et al., 2017). Interventions such as these may be of particular importance after retirement.

Results of our univariate and multivariate analyses further indicate that MD is greater among early retirees than among people who retire on time or later, as reported earlier (e.g. Rohwedder and Willis, 2010). Also, MD is greater among people who have retired earlier due to health problems, and among retirees who stay in retirement longer, in support of Mazzonna and Peracchi's (2017) findings. The decline in cognitive functioning that comes after leaving the workforce probably derives from the related losses of social relationships, purpose in life, self-esteem and decline in income, all of which are major contributors to people's subjective wellbeing (e.g. Carmel, 2001; Diener et al., 2003; Carmel et al., 2016). These factors, along with various indicators of subjective wellbeing, have significant direct and indirect effects on mental and physical health (e.g. Steptoe and Wardle, 2005; Blanchflower and Oswald, 2008; Tovel et al., 2017). Accordingly, and similar to previous reports (Davydow et al., 2014; Petersen et al., 2014; Baumgart et al., 2015; Alzheimer's Association, 2018), we also found significant associations between indicators of physical health/functioning and depression, and between depression evaluated at baseline, and MD after four years. These identified associations are in line with previous reports about the associations between depression and CD (e.g. Steffens and Potter, 2008; Dotson et al., 2010; Byers and Yaffe, 2011).

The bidirectional relationships between MD and physical or emotional health were also found in evaluating the changes in these variables over time, so that the greater the decline in physical health and functioning and in depressive symptoms during the four years of study, the greater the MD was. We also found support 
for previous reports on the attenuating power of both level of education and occupational attainments for CD (Livingston et al., 2017; Mazzonna and Peracchi, 2017). These repeated findings lend support to the theory of cognitive reserve, according to which people with high levels of education, and people who have careers with demanding intellectual requirements, accumulate a cognitive reserve that enables them to be more resilient in the face of degenerative brain changes (Ihle et al., 2016). The cognitive reserve often masks the underlying disease pathology (Meng and D'Arcy, 2012), causing steeper CD (Ihle et al., 2018) and delayed diagnoses of dementia (Stern, 2012). Accordingly, we found that type of occupation - white- versus blue-collar employment, which regularly correlates with level of education - has a unique contribution to $\mathrm{MD}$, so that $\mathrm{MD}$ is greater among bluecollar workers in comparison to white-collar workers. This finding contradicts the finding of Mazzonna and Peracchi (2017). However, our studies differ in almost all the methodologically important factors: the composition of the sample, the years of the SHARE data collection, the included countries, the outcome variable, and probably the internal composition and frequencies of the various occupations within each group of workers.

As expected, based on previous findings (e.g. Scarmeas and Stern, 2003; Adam et al., 2007; Hertzog et al., 2008; Banks and Mazzonna, 2012; Mazzonna and Peracchi, 2012; Meng and D'Arcy, 2012; Lifshitz-Vahav et al., 2017), an active physical and/or social lifestyle after retirement was also found to correlate with MD.

Following our division of European countries according to a classification based on four groupings of countries with similar socio-economic characteristics (Antonova et al., 2015), our results indicate that while the four regions do not differ in age or gender, retirees' memory is better and the level of education is higher in the Northern and Central countries compared to the Mediterranean countries. In addition, the highest percentage of early retirees is reported in Eastern countries, as well as the lowest percentage of participants who are employed at T2. Furthermore, our findings also show the highest prevalence of ADL limitations and depressive symptoms among retirees in this same block of countries. In addition, the percentage of people reporting at T2 that they are leading an active lifestyle is highest in Northern and Central European countries and lowest in the Mediterranean countries. All of these findings indicate that in comparison to the Northern and Central European nations, Eastern European nations and to a lesser degree the Mediterranean countries are disadvantaged in fundamental indicators of quality of life, including education and physical and mental health status. Furthermore, according to our findings and previous reports (e.g. Börsch-Supan et al., 2008; Mazzonna and Peracchi, 2012), these nations rank lowest on the factors that can attenuate $\mathrm{CD}$, including education level, retiring on time or later, and maintaining an active lifestyle. Thus, the identified differences in memory level between the Northern and Central European nations in comparison to the Eastern and Mediterranean nations can be partially explained by these nations' rankings on both types of factors: factors associated with $\mathrm{CD}$ and those associated with preservation of cognitive functions or postponing $\mathrm{CD}$.

Regarding MD over a four-year period, our findings indicate that the regional division of countries adds an additional unique and statistically significant contribution to the explanation of memory change, even when controlling for factors 
such as age, education, physical and mental health, early retirement, time from retirement, reason for retiring and active lifestyle, all of which are significantly associated with MD and well-established correlates of $\mathrm{CD}$. The contribution to the explanation of MD gained through dividing the examined countries into blocks, although relatively small, leads us to suggest the existence of additional sociocultural features relevant to MD. We grouped the various countries based mainly on a socio-economic perspective (Antonova et al., 2015). However, countries in the same blocks are also similar in social aspects, cultural perceptions, beliefs and the derived norms of behaviour, all of which are associated with $\mathrm{CD}$. For instance, compared to Northern European countries, in the Mediterranean countries older adults have higher expectations for close and warm family relations, including involvement in family matters and support in old age; probably because of this, they also experience higher levels of loneliness (Wallace et al., 2015). The difference in cultural perceptions of 'good retirement' in the various regions is another example which contributes to the understanding of our results regarding the difference between residents of Northern and Mediterranean nations in relation to leading an active lifestyle. While in Mediterranean nations retirement is generally viewed as a time of rest and relaxation, in the Northern countries it is viewed more as a period to enjoy leisure activities, physical exercise and volunteering (Börsch-Supan et al., 2008). Such unique features should be further explored in each of the four regions.

In sum, except for gender, each of our study variables had a significant unique contribution to the explanation of memory change after four years. However, although we have studied a relatively wide range of personal and nation-related factors, our multivariate regression models have explained 29-30 per cent of the variability in memory change over four years. This indicates that further multi-disciplinary research among ageing populations is needed in order to assess the additional combined genetic, psycho-social and socio-cultural features that directly or indirectly affect $\mathrm{MD}$ and $\mathrm{CD}$, and the degree and rate of changes in them over time.

Future studies should also refine the measures of some of the important contributors to cognitive functioning. For instance, we assessed active lifestyle as the number of types of activities in which a person is involved. Considering that lifestyles can be changed through relevant interventions, it is important to deepen the investigation of active lifestyle by increasing the number of studied activities and assessing which of the activities - and what intervals of participation - are effective in reducing $\mathrm{CD}$. The white- versus blue-collar jobs variable can also be improved by more specific evaluations of the various occupations included in each of these categories.

\section{Limitations of the study}

Our findings should be cautiously interpreted since we have focused only on a single dimension of cognition: working memory. This limitation prevents us from generalising our findings to a wider range of $\mathrm{CD}$. Furthermore, considering that in our study some participants experienced improvements in memory after four years, and based on previous reports indicating that $\mathrm{MD}$ or even a diagnosis of 
MCI can be reversed (Petersen et al., 2014), and despite our finding that the longer the period since retirement, the greater the $\mathrm{MD}$, we cannot assuredly predict the degree of further deterioration of cognitive functioning among retirees, in general, or among early retirees, in particular. Hence, future analyses using similar longitudinal data should examine changes in $\mathrm{MD}$ and $\mathrm{CD}$ over longer periods of time by using more than two measurements. Considering the apparent bidirectional associations of changes among physical health, depression and cognitive functioning (e.g. Byers and Yaffe, 2011; Livingston et al., 2017), and despite the longitudinal design of the study, we cannot disregard a potential reversed direction of causality from MD to decline in physical and mental health during the four years of the study. Generalisation of the results is also limited due to the attrition at T2 of retirees who were physically and cognitively weaker. In addition, measure of MD may be overly sensitive since change in memory from T1 to T2 is based on a change that can be as minimal as one word recalled/not recalled. However, even when we used a measure of two recalled/not recalled words instead of one, our results were similar in the hierarchical regression analyses. Furthermore, although we used a one-word scale and studied only a single facet of CD, the factors found to uniquely explain MD over time, while controlling for the wide range of other relevant factors (most of which are well established), indicate that such a minor change in recalled words may be a sign of further CD. We hence suggest considering the studied factors for prevention and treatment of CD.

\section{Conclusion}

Although there is still much more to learn about the phenomenon of CD over time in older adults, our longitudinal findings show that declines in physical and emotional health and functioning negatively correlate with $\mathrm{MD}$, while education and active lifestyle, through re-employment or other physical/social activities, attenuate these associations. Our comparative analyses among blocks of countries indicate that the quality of a country's educational and medical systems is related to the cognitive functioning of its citizens. Moreover, our analyses show that early retirement plays a unique and important role in $\mathrm{MD}$, and that this occurs in each of the studied European regions even when controlling for many relevant personal and behavioural factors. These findings lend support to our hypotheses and lead us to suggest postponing $\mathrm{CD}$ by focusing on what we know through repeated findings and are able to implement.

Considering that $\mathrm{CD}$ is a multifactorial phenomenon, nations can act on several levels, including promoting policies directed towards prolonging years of mandatory and free education and improving their health systems (Livingston et al., 2017). Through laws, pension and taxation policies, nations can increase the number of years of participation in the workforce (Rechel et al., 2013). In addition to raising the age of mandatory retirement or cancelling it, nations can introduce policies and programmes designed to encourage people to postpone retirement, for instance, by adjusting work conditions to accommodate the inevitable physical and mental changes which occur at older ages. Changing cultural beliefs and behaviours is difficult, but if such changes are related to health, they can be achieved through public health education messages and primary/secondary prevention 
programmes. We also suggest promoting interventions which have been reported to be effective in improving cognitive functioning among people with $\mathrm{MCI}$, including interventions based on cognitive exercise (e.g. Belleville et al., 2006), physical exercise (e.g. Smith et al., 2013) or combined methods (e.g. Byers and Yaffe, 2011; Ngandu et al., 2015; Köbe et al., 2016; Livingston et al., 2017). For example, maintaining an active lifestyle and physical health can be facilitated by making exercise facilities and training personnel available and accessible in public settings. Implementing such policies and interventions seems to be of special importance for Mediterranean and Eastern European nations.

Acknowledgements. This paper uses data from SHARE Waves 1, 2 and 4 (DOIs: 10.6103/ SHARE.w1.710, 10.6103/SHARE.w2.710, 10.6103/SHARE.w4.710), see Börsch-Supan et al. (2013) for methodological details. The SHARE data collection has been funded by the European Commission through FP5 (QLK6-CT-2001-00360), FP6 (SHARE-I3: RII-CT-2006-062193, COMPARE: CIT5-CT-2005-028857, SHARELIFE: CIT4 CT-2006-028812), FP7 (SHARE-PREP: GA N²11909, SHARE-LEAP: GA N²27822, SHARE M4: GA N²61982, DASISH: GA N²83646) and Horizon 2020 (SHARE-DEV3: GA Nº76536, SHARE-COHESION: GA N870628, SERISS: GA N654221, SSHOC: GA $\mathrm{N}^{\circ} 823782$ ) and by DG Employment, Social Affairs \& Inclusion. Additional funding from the German Ministry of Education and Research, the Max Planck Society for the Advancement of Science, the U.S. National Institute on Aging (U01_AG09740-13S2, P01_AG005842, P01_AG08291, P30_AG12815, R21_AG025169, Y1-AG4553-01, IAG_BSR06-11, OGHA_04-064, HHSN271201300071C) and from various national funding sources is gratefully acknowledged (see www.share-project.org). This study was supported by the Center for Multidisciplinary Research in Aging of Ben-Gurion University of the Negev. The authors would like to thank Michelle Levenson and Sara Pollack for their assistance with article preparation.

Financial support. This research received no specific grant from any funding agency in the public, commercial or not-for-profit sectors.

Conflict of interest. The authors declare no potential conflicts of interest with respect to the research, authorship and/or publication of this article.

Ethical standards. Ethical approval was not required for this study.

\section{References}

Adam S, Bonsang E, Germain S and Perelman S (2007) Retirement and cognitive reserve: a stochastic frontier approach applied to survey data. HEC-ULg, Liège, Belgium, CREPP Working Paper 2007/04.

Alzheimer's Association (2018) 2018 Alzheimer's disease facts and figures. Alzheimer's \& Dementia 14, 367-429.

Antonova L, Aranda L, Havari E and Pace N (2015) Is there a European land of opportunity? Cross-country differences in inter-generational mobility in 14 European countries and Israel. In A. Borsch-Supan, T. Kneip, H. Litwin, M. Myck, \& G. Weber (eds.) Ageing in Europe-Supporting Policies for an Inclusive Society (pp. 209-222). Walter de Gruyter GmbH \& Co., Berlin.

Banks J and Mazzonna F (2012) The effect of education on old age cognitive abilities: evidence from a regression discontinuity design. The Economic Journal 122, 418-448.

Baumgart M, Snyder HM, Carrillo MC, Fazio S, Kim H and Johns H (2015) Summary of the evidence on modifiable risk factors for cognitive decline and dementia: a population-based perspective. Alzheimer's \& Dementia 11, 718-726.

Belleville S, Gilbert B, Fontaine F, Gagnon L, Ménard É and Gauthier S (2006) Improvement of episodic memory in persons with mild cognitive impairment and healthy older adults: evidence from a cognitive intervention program. Dementia and Geriatric Cognitive Disorders 22, 486-499.

Blanchflower DG and Oswald AJ (2008) Hypertension and happiness across nations. Journal of Health Economics 27, 218-233. 
Bonsang E, Adam S and Perelman S (2012) Does retirement affect cognitive functioning? Journal of Health Economics 31, 490-501.

Börsch-Supan A, Brugiavini A, Jürges H, Kapteyn A, Mackenbach J, Siegrist J and Weber G (eds) (2008) First Results from the Survey of Health, Ageing and Retirement in Europe (2004-2007): Starting the Longitudinal Dimension. Mannheim, Germany: Mannheim Research Institute for the Economics of Aging.

Börsch-Supan A, Brandt M, Hunkler C, Kneip T, Korbmacher J, Malter F, Schaan B, Stuck S and Zuber S (2013) Data resource profile: the Survey of Health, Ageing and Retirement in Europe (SHARE). International Journal of Epidemiology 42, 992-1001.

Byers AL and Yaffe K (2011) Depression and risk of developing dementia. Nature Reviews Neurology 7 , 323-331.

Carmel S (2001) The will to live: gender differences among elderly persons. Social Science \& Medicine 52, 949-958.

Carmel S, Granek L and Zamir A (2016) Influences of nationalism and historical traumatic events on the will to live of elderly Israelis. The Gerontologist 56, 753-761.

Coe NB, von Gaudecker HM, Lindeboom M and Maurer J (2012) The effect of retirement on cognitive functioning. Health Economics 21, 913-927.

Davydow DS, Zivin K, Katon WJ, Pontone GM, Chwastiak L, Langa KM and Iwashyna TJ (2014) Neuropsychiatric disorders and potentially preventable hospitalizations in a prospective cohort study of older Americans. Journal of General Internal Medicine 29, 1362-1371.

De Ronchi D, Palmer K, Pioggiosi P, Atti AR, Berardi D, Ferrari B, Dalmonte D and Fratiglioni L (2007) The combined effect of age, education, and stroke on dementia and cognitive impairment no dementia in the elderly. Dementia and Geriatric Cognitive Disorders 24, 266-273.

Diener E, Oishi S and Lucas RE (2003) Personality, culture, and subjective well-being: emotional and cognitive evaluations of life. Annual Review of Psychology 54, 403-425.

Ding D, Zhao Q, Qihao Guo Q, Meng H, Wang B, Luo J, Mortimer JA, Borenstein AR and Hong Z (2015) Prevalence of mild cognitive impairment in an urban community in China: a cross-sectional analysis of the Shanghai Aging Study. Alzheimer's \& Dementia 11, 300-309.

Dotson VM, Beydoun MA and Zonderman AB (2010) Recurrent depressive symptoms and the incidence of dementia and mild cognitive impairment. Neurology 75, 6-34.

Dufouil C, Pereira E, Chêne G, Glymour MM, Alpérovitch A, Saubusse E, Risse-Fleury M, Heuls B, Salord JC, Brieu MA and Forette F (2014) Older age at retirement is associated with decreased risk of dementia. European Journal of Epidemiology 29, 353-361.

Enache D, Winblad B and Aarsland D (2011) Depression in dementia: epidemiology, mechanisms, and treatment. Current Opinion in Psychiatry 24, 461-472.

Ferri CP, Prince M, Brayne C, Brodaty H, Fratiglioni L, Ganguli M, Hall K, Hasegawa K, Hendrie H, Huang Y and Jorm A (2005) Global prevalence of dementia: a Delphi consensus study. The Lancet 366, 2112-2117.

Fisher GG, Stachowsky A, Infurna FJ, Faul JD, Grosch J and Tetrick LE (2014) Mental health demand, retirement, and longitudinal trajectories of cognitive functioning. Journal of Occupational Health Psychology 19, 231-242.

Fong TG, Tulebaev SR and Inouye SK (2009) Delirium in elderly adults: diagnosis, prevention and treatment. Nature Reviews Neurology 5, 210-220.

George LK and Gwyther LP (1986) Caregiver well-being: a multidimensional examination of family caregivers of demented adults. The Gerontologist 26, 253-259.

Hebert LE, Scherr PA, McCann JJ, Beckett LA and Evans DA (2001) Is the risk of developing Alzheimer's disease greater for women than for men? American Journal of Epidemiology 153, 132-136.

Hertzog C, Kramer A, Wilson R and Lindenberger U (2008) Enrichment effects on adult cognitive development: can the functional capacity of older adults be preserved and enhanced? Psychological Science in the Public Interest 9, 1-65.

Hultsch DF, Hertzog C, Small BJ and Dixon RA (1999) Use it or lose it: engaged lifestyle as a buffer of cognitive decline in aging. Psychology and Aging 14, 245-263.

Ihle A, Oris M, Fagot D, Maggiori C and Kliegel M (2016) The association of educational attainment, cognitive level of job, and leisure activities during the course of adulthood with cognitive performance in old age: the role of openness experience. International Psychogeriatrics 28, 733-740. 
Ihle A, Ghisletta P, Ballhausen N, Fagot D, Vallet F, Baeriswyl M, Sauter J, Oris M, Maurer J and Kliegel M (2018) The role of cognitive reserve accumulated in midlife for the relation between chronic diseases and cognitive decline in old age: a longitudinal follow-up across six years. Neuropsychologia 121, 37-46.

Köbe T, Witte AV, Schnelle A, Lesemann A, Fabian S, Tesky VA, Pantel J and Flöel A (2016) Combined omega-3 fatty acids, aerobic exercise and cognitive stimulation prevents decline in gray matter volume of the frontal, parietal and cingulate cortex in patients with mild cognitive impairment. Neuroimage 131, $226-238$.

Koepsell TD and Monsell SE (2012) Reversion from mild cognitive impairment to normal or near-normal cognition: risk factors and prognosis. Neurology 79, 1591-1598.

Lifshitz-Vahav H, Shrira A and Bodner E (2017) The reciprocal relationship between participation in leisure activities and cognitive functioning: the moderating effect of self-rated literacy level. Aging \& Mental Health 21, 524-531.

Litwin $\mathbf{H}$ and Tur-Sinai A (2015) The role of the social network in early retirement among older Europeans. Work, Aging, and Retirement 1, 340-349.

Livingston G, Sommerlad A, Orgeta V, Costafreda SG, Huntley J, Ames D, Ballard C, Banerjee S, Burns A and Cohen-Mansfield J (2017) The Lancet International Commission on Dementia Prevention and Care. The Lancet 390, 2673-2734.

Mangin D, Bahat G, Golomb BA, Mallery LH, Moorhouse P, Onder G, Petrovic M and Garfinkel D (2018) International Group for Reducing Inappropriate Medication Use \& Polypharmacy (IGRIMUP): position statement and 10 recommendations for action. Drugs \& Aging 35, 575-587.

Mazzonna F and Peracchi F (2012) Aging, cognitive abilities and retirement. European Economic Review 56, 691-710.

Mazzonna F and Peracchi F (2017) Unhealthy retirement? Journal of Human Resources 52, 128-151.

Meng X and D'Arcy C (2012) Education and dementia in the context of the cognitive reserve hypothesis: a systematic review with meta-analyses and qualitative analyses. PLOS ONE 7, e38268.

Meng A, Nexo MA and Borg V (2017) The impact of retirement on age related cognitive decline - a systematic review. BMC Geriatrics 17, 160, 1-10.

Ngandu T, Lehtisalo J, Solomon A, Levälahti E, Ahtiluoto S, Antikainen R, Bäckman L, Hänninen T, Jula A, Laatikainen T and Lindström J (2015) A 2 year multidomain intervention of diet, exercise, cognitive training, and vascular risk monitoring versus control to prevent cognitive decline in at-risk elderly people (FINGER): a randomised controlled trial. The Lancet 385, 2255-2263.

Nyberg L, Lövdén M, Riklund K, Lindenberger U and Bäckman L (2012) Memory aging and brain maintenance. Trends in Cognitive Sciences 16, 292-305.

Paterniti S, Verdier-Taillefer MH, Dufouil C and Alpérovitch A (2002) Depressive symptoms and cognitive decline in elderly people: longitudinal study. British Journal of Psychiatry 181, 406-410.

Petersen RC, Caracciolo B, Brayne C, Gauthier S, Jelic V and Fratiglioni L (2014) Mild cognitive impairment: a concept in evolution. Journal of Internal Medicine 275, 214-228.

Petersen RC, Lopez O, Armstrong MJ, Getchius TS, Ganguli M, Gloss D, Gronseth GS, Marson D, Pringsheim T, Day GS and Sager M (2018) Practice guideline update summary: mild cognitive impairment. Report of the Guideline Development, Dissemination, and Implementation Subcommittee of the American Academy of Neurology. Neurology 90, 1-10.

Prince MJ, Reischies F, Beekman AT, Fuhrer R, Jonker C, Kivela SL, Lawlor BA, Lobo A, Magnusson H, Fichter M and Van Oyen H (1999) Development of the EURO-D scale - a European Union initiative to compare symptoms of depression in 14 European centers. British Journal of Psychiatry 174, 330-338.

Rechel B, Grundy E, Robine JM, Cylus J, Mackenbach JP, Knai C and McKee M (2013) Ageing in the European Union. The Lancet 381, 1312-1322.

Reisberg B, Ferris SH, De Leon MJ and Crook T (1982) The global deterioration scale for assessment of primary degenerative dementia. American Journal of Psychiatry 139, 1136-1139.

Roberts R and Knopman DS (2013) Classification and epidemiology of MCI. Clinics in Geriatric Medicine 29, 753-772.

Rohwedder S and Willis RJ (2010) Mental retirement. Journal of Economic Perspectives 24, 119-138.

Salthouse TA (1985) A Theory of Cognitive Ageing. Amsterdam: North Holland.

Salthouse TA (2006) Mental exercise and mental aging: evaluating the validity of the 'use it or lose it' hypothesis. Perspectives on Psychological Science 1, 68-87. 
Scarmeas N and Stern Y (2003) Cognitive reserve and lifestyle. Journal of Clinical and Experimental Neuropsychology 25, 625-633.

Schaie KW (1989) The hazards of cognitive ageing. The Gerontologist 29, 484-493.

Smith JC, Nielson KA, Antuono P, Lyons JA, Hanson RJ, Butts AM, Hantke NC and Verber MD (2013) Semantic memory functional MRI and cognitive function after exercise intervention in mild cognitive impairment. Journal of Alzheimer's Disease 37, 197-215.

Spaniol J, Madden DJ and Voss A (2006) A diffusion model analysis of adult age differences in episodic and semantic long-term memory retrieval. Journal of Experimental Psychology: Learning, Memory, and Cognition 32, 101-117.

Steffens DC and Potter GG (2008) Geriatric depression and cognitive impairment. Psychological Medicine 38, $163-175$.

Steptoe A and Wardle J (2005) Positive affect and biological function in everyday life. Neurobiology of Aging 26, S108-S112.

Stern Y (2012) Cognitive reserve in ageing and Alzheimer's disease. The Lancet Neurology 11, 1006-1012.

Tovel H, Carmel S and Raveis HR (2017) Relationships among self-perception of aging, physical functioning, and self-efficacy in late life. Journals of Gerontology: Psychological Sciences and Social Sciences 74B, 212-221.

Tulving E (1995) Organization of memory: quo vadis. In Gazzaniga MS (ed.), The Cognitive Neurosciences. Cambridge, MA: MIT Press, pp. 839-847.

Wallace LM, Theou O, Pena F, Rockwood K and Andrew MK (2015) Social vulnerability as a predictor of mortality and disability: cross-country differences in the Survey of Health, Aging, and Retirement in Europe (SHARE). Aging Clinical and Experimental Research 27, 365-372.

Ward A, Arrighi HM, Michels S and Cedarbaum JM (2012) Mild cognitive impairment: disparity of incidence and prevalence estimates. Alzheimer's \& Dementia 8, 14-21.

Winblad B, Amouyel P, Andrieu S, Ballard C, Brayne C, Brodaty H and Fratiglioni L (2016) Defeating Alzheimer's disease and other dementias: a priority for European science and society. The Lancet Neurology 15, 455-532.

World Health Organization (WHO) (2017a) Dementia. Geneva: WHO. Available at http://www.who.int/ news-room/fact-sheets/detail/dementia.

World Health Organization (WHO) (2017b) Mental Health and Older Adults. Geneva: WHO. Available at http://www.who.int/news-room/fact-sheets/detail/mental-health-of-older-adults.

Zeng Y, Feng Q, Hesketh T, Christensen K and Vaupel JW (2017) Survival, disabilities in activities of daily living, and physical and cognitive functioning among the oldest-old in China: a cohort study. The Lancet 389, 1619-1629.

Zulka LE, Hansson I and Hassing LB (2019) Impact of retirement on cognitive function. GeroPsych 32, 187-203.

Cite this article: Carmel S, Tur-Sinai A (2022). Cognitive decline among European retirees: impact of early retirement, nation-related and personal characteristics. Ageing \& Society 42, 2343-2369. https://doi.org/ $10.1017 /$ S0144686X21000064 